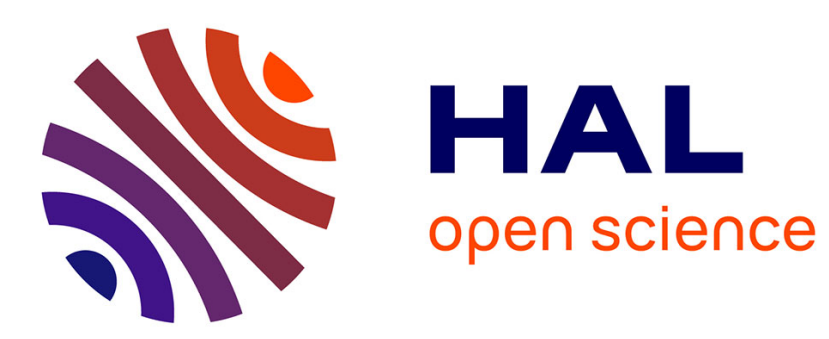

\title{
Augmented Reality Media for Cultural Experience in Shrines
}

Kei Kobayashi, Junichi Hoshino

\section{To cite this version:}

Kei Kobayashi, Junichi Hoshino. Augmented Reality Media for Cultural Experience in Shrines. 16th International Conference on Entertainment Computing (ICEC), Sep 2017, Tsukuba City, Japan. pp.375-378, 10.1007/978-3-319-66715-7_43 . hal-01771230

\section{HAL Id: hal-01771230 \\ https://hal.inria.fr/hal-01771230}

Submitted on 19 Apr 2018

HAL is a multi-disciplinary open access archive for the deposit and dissemination of scientific research documents, whether they are published or not. The documents may come from teaching and research institutions in France or abroad, or from public or private research centers.
L'archive ouverte pluridisciplinaire HAL, est destinée au dépôt et à la diffusion de documents scientifiques de niveau recherche, publiés ou non, émanant des établissements d'enseignement et de recherche français ou étrangers, des laboratoires publics ou privés.

\section{(c)(1)}

Distributed under a Creative Commons Attribution| 4.0 International License 


\title{
Augmented Reality Media for Cultural Experience in Shrines
}

\author{
Kei Kobayashi ${ }^{1}$ and Junichi Hoshino ${ }^{1}$ \\ ${ }^{1}$ University of Tsukuba, Graduate school of Systems and Information Engineering, \\ 1-1-1, Tennodai, Tsukuba-shi, Ibaraki, Japan \\ kobayashi.kei@entcomp.esys.tsukuba.ac.jp,jhoshino@esys.tsukuba.ac.jp
}

\begin{abstract}
While intangible culture still remains as a custom, it is gradually losing the substance making it difficult for people to understand the value by their sensibility. Sensibility is important for conservation and dissemination of culture as well as cultural industry, and the augmented reality media convey meaning of shrine rituals, style of ritual manners and meaning as well as information about enshrined deities while appealing to people's sensibility. Media for the purpose consist of five works mixed with attractiveness of materials and system development. Users are supposed to experience the works sequentially by holding a scroll painting. The scroll painting is a centerpiece to be used, for example, as a screen for projecting works guide and images.
\end{abstract}

Keywords: Culture, Interaction, Media Art, Texture, Augmented Reality

\section{Introduction}

Japanese culture is expected to be disseminated to the world as a cultural industry's strategy by reaffirming and evaluating its own attractiveness. In this paper, we propose augmented reality media for shrines to convey intangible culture. As a part of traditionally continuous Japanese culture, shrines have taken roots in customs including New Year's visit and tourism even in modern times. However, less people know how to offer prayers correctly and what is enshrined. With a scroll drawing in their hands, users are able to obtain information easier in a step-by-step manner by sequentially experiencing spatial media consisting of multiple works based on images and graphic design as well as to learn subjects, styles and meaning of manners in shrines with their sensibility by experiencing prayer.

\section{System Overview}

Media to be proposed is centered by scroll drawing Fig. 1. Space consists of five elements; i.e. Origami paper of pigeon as shinshi (Divine servant) of subject shrine with the meaning of rituals described thereon, flag to show information of enshrined deity, image operated by projecting detail of the enshrined deity and laying on of hands, animation of manner at Chozusha (purification trough) similarly projected on the scroll drawing, and animation of manner at a hall for worship projected on an acryl plate in order. 

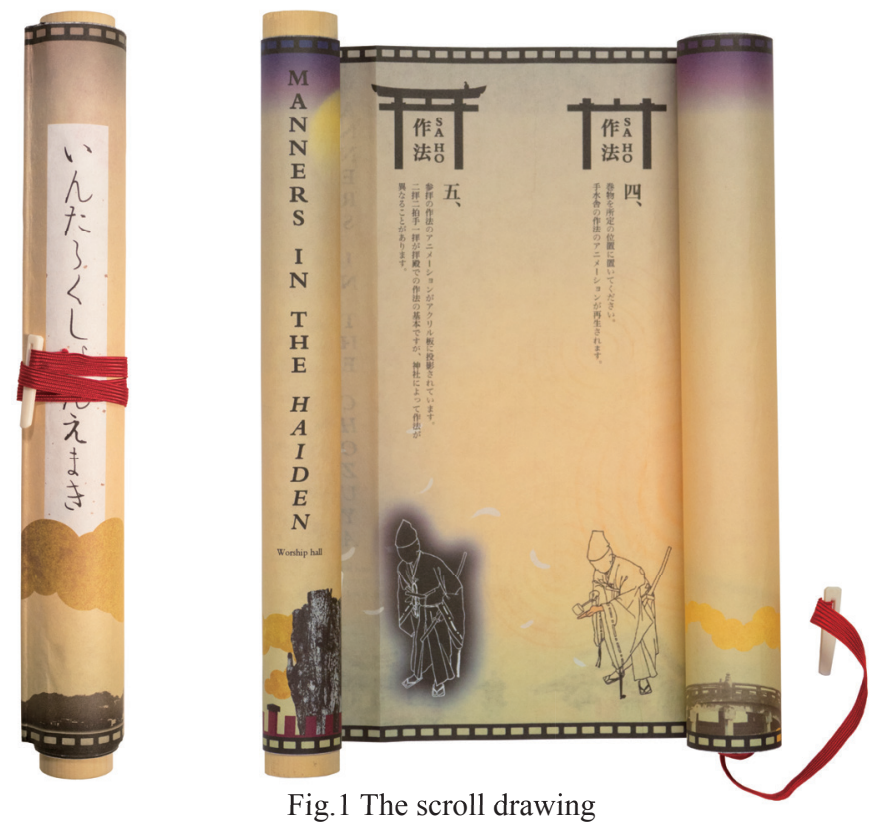

In work Fig. 2 operated by projecting images on the scroll drawing for constructing a system, a framework was detected by RGB-D camera. With a coordinate designated for an icon projected on the scroll drawing by a projector, it was set up to replay a special effect by switching projected image when right or left hand entered into a range of the coordinate. With an idea that visual presentation is better to convey behaviors than a text, manners at Chozusha were expressed by animation and position at starting animation was changed by coordinates evenly divided for seek bar operation. In addition, such a function to temporary stop by grabbing a hand and to replay by unclenching the fist was equipped with in addition to the seek bar.
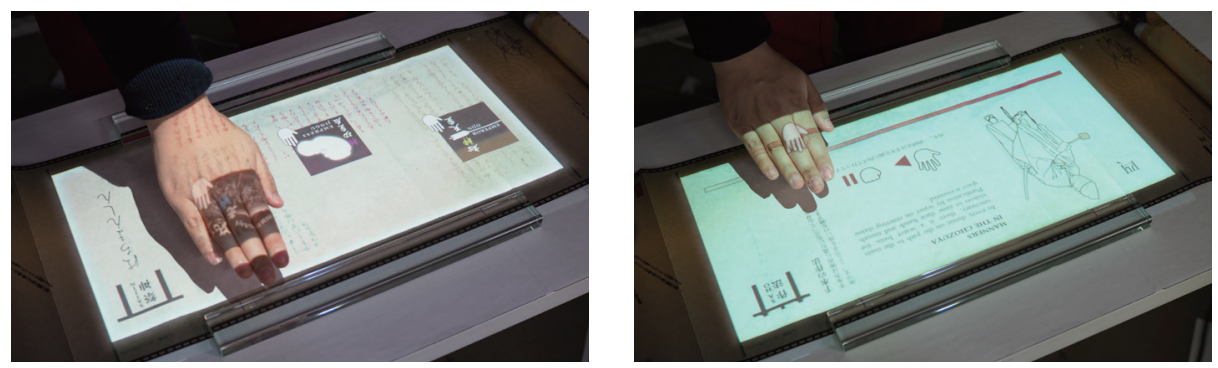

Fig. 2 Works using a system

For instruct manners at a hall for worship, a method to project images on a rear permeable film put on a transparent acryl plate was adopted. The screen is capable of making users feel uncanny aura of mystery without rupturing space while making matters appear to be floating visually compared with ordinary screen (Fig. 3). 

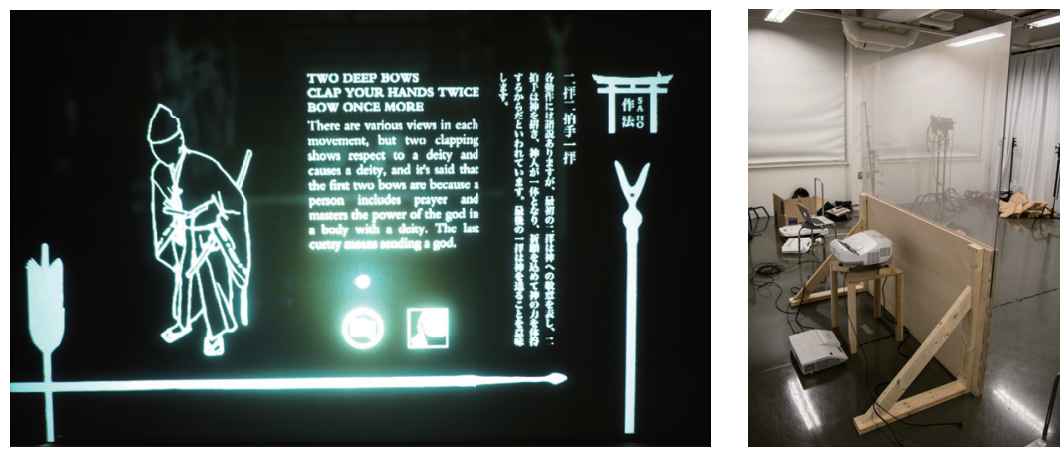

Fig.3 Manners at a hall for worship

\section{Experiments}

Data was gathered from 12 persons who actually experienced a work by questionnaire about before and after they experienced the work (Fig. 4). In order to confirm their degree of understanding of shrines before they view the work, we asked them to select from among four grades, i.e. "1. I know," "2. If anything, I know," “3. If anything, I don't know," and "4. I don't know," for questions on style and meaning of manners and what is enshrined as deity, respectively. As a result, about half of them responded as "If anything, I know" about style of the manners and what is enshrined but majority of them responded as "I don't know" about meaning of the manners (Fig. 5).

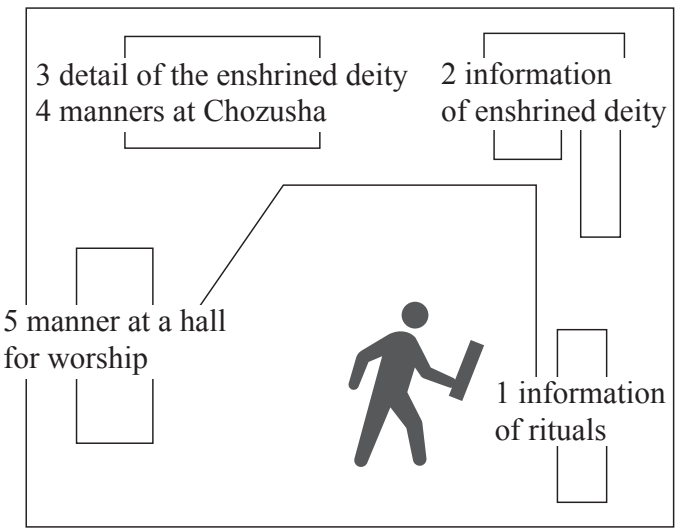

Fig.4 Experiment environment

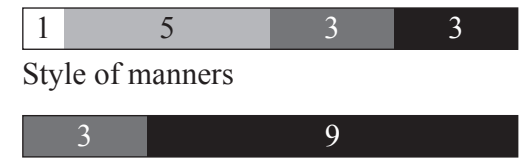

Meaning of manners

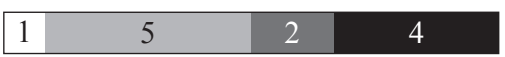

What is enshrined as deity

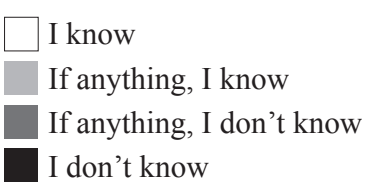

Fig.5 Data before the works

After they viewed the work, we asked them to evaluate by four grades, i.e. "1. I understood," "2. I understood to some extent," "3. I didn't understand well," and "4. I didn't understand," and to describe the reasons in order to confirm their degree of understanding about style and meaning of the manners. The result was that all responses were made up by " 1 . I understood," and " 2 . I understood to some extent" (Fig. 6). As the reason why they could understand, many of them described effect of animation. Some of them responded that they obtained information, which they might 
have not read by a text alone, with an interest due to the interactive method.

In order to recognize importance $f$ manners relatively, we asked them to evaluate seven items in total, i.e. "Omikuji (paper fortune)", "Items including Omamori (charm) and Ema (votive horse tablets)", "Money offerings", "wish", "manners", "Timing for visiting" and "Existence as a specific shrine" on a 5-point scale (Fig. 7). The result was compared by average values. Before viewing work, "wish" was the highest by a score of 4 and "manners" was the fifth position by 2.66. In the same question after viewing the work, "manners" increased to 3.66. "Existence as a specific shrine" showed large difference next to manners before and after viewing the work. It is considered that it had an effect to make them conscious about characteristics of the shrines such as enshrined deity because the work took up a specific shrine as the theme.

\begin{tabular}{l}
\hline 4 \\
\hline Style and meaning of the manners \\
$\square$ I understood \\
I understood to some extent \\
I didn't understand well \\
I didn't understand \\
\hline 4 \\
\hline Effect of interaction \\
$\square$ I was interested \\
I was interested to some extent \\
I was not very interested \\
I was not interested
\end{tabular}

Fig.6 Data after the works

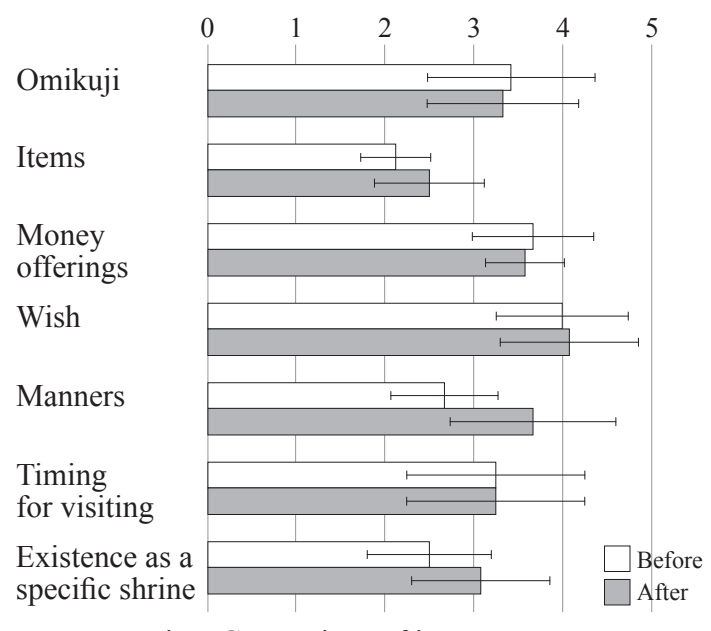

Fig.7 Comparison of importance

\section{Conclusion}

In the current study, we have created sequentially augmented reality media taking up shrines as a theme based on a notion that something intangible and sensitivity for it is important for conservation and dissemination of culture and cultural industry.

From a questionnaire survey conducted for those who experienced, it has been proved that shrines are a culture remaining as a part of custom but its meaning is fading while losing the substance in reality. In addition, it is interactive to convey manners and their meanings through targeted works and it has been achieved sufficiently by dynamic visual manner resulting in its increased importance.

\section{Reference}

[1] Christoph Bartneck, Jun Hu, Ben Salem, Razvan Cristescu, Matthias Rauterberg: Applying Virtual and Augmented Reality in Cultural Computing; The International Journal of Virtual Reality(2008) 